\title{
PERANCANGAN SISTEM INFORMASI PEREKRUTAN KARYAWAN BERBASIS WEB MENGGUNAKAN PHP DAN MYSQL DI PT. RIA INDAH MANDIRI
}

\author{
Ardelia Astriany Rizky ${ }^{1}$, Irfan Ramdhani ${ }^{2}$ \\ Teknik Infomatika Politeknik Piksi Ganesha ${ }^{1}$, \\ Manajemen Informatika Politeknik Piksi Ganesha ${ }^{2}$ \\ e-mail: ardelia.astriany@gmail.com ${ }^{1}$,irfanramdhanirb@gmail.com²
}

\begin{abstract}
ABSTRAK
Penelitian ini bertujuan untuk menganalisis Sistem Informasi perekrutan Karyawan baru di PT Ria Indah Mandiri yang saat ini masih manual dan belum terkomputerisasi, dimana sistem perekrutan karyawan yang berjalan saat ini menyebabkan kurang efektifnya dalam proses penseleksian dan terjadinya penumpukan arsip lamaran kerja. Untuk mengatasi permasalahan tersebut dibangunlah Sistem Informasi Rekrutmen Karyawan Berbasis Web. Sistem Informasi yang dibangun ini menggunakan pemograman PHP dan MySQL database server. Metode pengembangan Perangkat Lunak yang digunakan adalah Waterfall, dengan Teknik pengumpulan data berupa Observasi, Kajian Pustaka dan Wawancara. Dengan Sistem Informasi baru ini diharapkan dapat membuat Proses Perekrutan Karyawan baru lebih Efektif dan Efisien baik dalam proses Penseleksian maupun Sistem Pengambilan keputusannya.
\end{abstract}

Kata Kunci: Sistem Informasi berbasis Web, Perekrutan Karyawan, PHP dan MySQL

\section{PENDAHULUAN}

Salah satu kegiatan paling penting dalam suatu perusahaan atau organisasi adalah masalah sumber daya manusia. Karena, fokus utama manajemen sumber daya manusia adalah memberikan kontribusi sukses atau tidaknya suatu perusahaan. Manajemen sumber daya manusia sendiri tidak hanya mengatur karyawan yang ada dalam perusahaan, tetapi dimulai dari pemilihan calon karyawan, penilaian suatu kinerja karyawan, pemilihan dan penempatan karyawan serta pengisian jabatan manajerial sesuai dengan kepatutan dan kelayakan.

Proses perekrutan karyawan merupakan tahap yang strategis untuk mengidentifikasi calon yang tepat. Hal yang sama juga diungkap oleh seorang peneliti bahwa proses perekrutan karyawan baru ikut andil dalam mengambil kebijakan organisasi. Tujuan utama dalam proses perekrutan karyawan baru adalah untuk mendapatkan orang yang tepat pada penempatan yang tepat pula sehingga sesuai dengan kondisi dan kebutuhan organisasi atau perusahaan (Suhendra, 2006). Perusahaan yang baik akan senantiasa mencari individuindividu yang mempunyai etos kerja yang baik. Sehingga, ketika hal tersebut telah dimiliki oleh sebuah organisasi atau perusahaan maka ia akan mampu bertahan ditengah persaingan dengan penuh kompetisi dan perubahan yang begitu cepat.

Untuk mampu bertahan ditengah persaingan perusahaan dalah hal pengelolaan Sumber Daya. Salah satu hal yang dapat dilakukan adalah menerapkan Sistem Informasi berbasis Web, Sistem informasi berbasis web yang dibangun ini adalah untuk menggantikan pengelolaan Sumber Daya secara manual. Salah satunya sistem perekrutan karyawan manual ini menyebabkan kurang efektifnya dalam proses publikasi lowongan, proses penseleksian dan terjadinya penumpukan arsip lamaran kerja. Untuk mengatasi permasalahan tersebut dibangunlah Sistem Informasi Rekrutmen Karyawan Berbasis Web. 


\section{LANDASAN TEORI \\ 2.1 Rekrutmen}

Pengertian rekrutmen adalah putusan sumber daya manusia (SDM) berupa banyak dibutuhkan, kapan dibutuhkan, serta pengetahuan, keterampilan, kemampuan khusus yang dimiliki. Perekrutan karyawan merupakan suatu proses atau tindakan yang dilakukan oleh organisasi untuk mendapatkan tambahan karyawan melalui beberapa tahapan mencakup identifikasi dan evaluasi sumber-sumber perekrutan tenaga kerja, menentukan kebutuhan tenaga kerja, proses seleksi, penempatan, dan orientasi tenaga kerja. Perekrutan karyawan bertujuan menyediakan karyawan yang cukup agar manajemen dapat memilih karyawan yang memenuhi kualifikasi yang mereka perlukan (Maltis,2001).

Rekrutmen merupakan proses komunikasi dua arah. Para pelamar menghendaki informasi yang akurat mengenai seperti apakah rasanya bekerja di dalam organisasi bersangkutan. Organisasi-organisasi sangat menginginkan informasi yang akurat tentang seperti apakah pelamar-pelamar tersebut jika kelak mereka diangkat sebagai karyawan.

Agar kualitas tenaga kerja yang diperoleh sesuai dengan keinginan perusahaan, maka terlebih dahulu perusahaan harus memilih sumber-sumber tenaga kerja yang tersedia. Pemilihan sumber-sumber tenaga kerja sangat penting mengingat jika salah dalam pemilihan sumber tenaga kerja akan berakibat fatal yaitu memperoleh tenaga kerja yang tidak sesuai dengan harapan. (Kasmir, 2002) "Perekrutan (recruitment) karyawan merupakan suatu proses atau tindakan yang dilakukan oleh organisasi untuk mendapatkan tambahan karyawan melalui tahapan empat yaitu:

\subsection{Identifikasi dan Evaluasi}

Tahap identifikasi merupakan tahap awal dari proses yang terdiri atas penentuan dari unsur-unsur yang diamati. Kegiatan ini diawali dengan melakukan analisis pekerjaan agar dapat mengenali unsur-unsur yang dapat dinilai dan dapat mengembangkan skala penilaian. Dalam kaitannya dengan pihak penilai, identifikasi berarti bahwa bagaimanapun pihak penilai harus dapat menentukan unsur-unsur yang dinilai dari yang dinilai. Tentu saja, apa yang akan dinilai adalah yang berkaitan dengan pekerjaan, bukan yang tidak berkaitan dengan pekerjaan.Selanjutnya, diadakan evaluasi. Dengan diadakannya evaluasi, berarti ada pengamatan secara seksama dan periodik. Semua unsur yang dinilai harus diamati secara seksama agar dapat dibuat penilaian yang wajar dan tepat.

\subsection{Proses Seleksi}

Seleksi merupakan proses pemilihan orang-orang yang memiliki kualifikasikualifikasi yang dibutuhkan untuk mengisis lowongan pekerjaan di sebuah organisasi (Malthis, 2006). Seleksi lebih dari sekedar pemilihan orang yang tersedia. Menyeleksi sekumpulan pengetahuan, keahlian, dan kemampuan yang sesuai merupakan suatu paket yang terdapat pada manusia untuk memperoleh "kecocokan" antara apa yang sesungguhnya dapat dilakukan dan apa yang ingin dilakukan pelamar. Adapun proses seleksi yang lazim dipergunakan oleh perusahaan, prosedurnya meliputi:

1. Wawancara awal

2. Pengisian formulir

3. Pemeriksaan referensi

4. Test psikologi

5. Wawancara/ interview

6. Persetujuan atasan langsung 
7. Pemeriksaan kesehatan

8. Indeks atau orientasi

\subsection{Website}

Secara umum, website (web) dipahami sebagai sekumpulan halaman yang terdiri dari beberapa laman yang berisi informasi dalam bentuk digital baik itu teks, gambar, animasi yang disediakan melalui jalur internet sehingga dapat diakses dari seluruh dunia yang memiliki koneksi internet. Website awalnya merupakan suatu layanan sajian informasi yang menggunakan konsep hyperlink, yang memudahkan surfer atau pengguna internet melakukan penelusuran informasi di internet. Informasi yang disajikan dengan web menggunakan konsep multimedia, informasi dapat disajikan dengan menggunakan banyak media, seperti teks, gambar, animasi, suara, atau film.

Website adalah kumpulan halaman web yang saling terhubung dan file-filenya saling terkait. Web terdiri dari page atau halaman, dan kumpulan halaman yang dinamakan homepage. Homepage berada pada posisi teratas, dengan halaman-halaman terkait berada di bawahnya. Biasanya setiap halaman di bawah homepage disebut child page, yang berisi hyperlink ke halaman lain dalam web (Gregorius, 2000:30).

Website merupakan fasilitas internet yang menghubungkan dokumen dalam lingkup lokal maupun jarak jauh. Dokumen pada website disebut dengan web page dan link dalam website memungkinkan pengguna bisa berpindah dari satu page ke page lain (hyper text), baik diantara page yang disimpan dalam server yang sama maupun server diseluruh dunia. Pages diakses dan dibaca melalui browser seperti Netscape Navigator, Internet Explorer, Mozila Firefox, Google Chrome dan aplikasi.

\section{METODE PENELITIAN}

\subsection{Waterfall}

Model ini pertama kali yang diperkenalkan oleh Winston Royce sekitar tahun 1970 sehingga sering dianggap kuno, tetapi merupakan model yang paling banyak dipakai didalam Software Engineering (SE). Model ini melakukan pendekatan secara sistematis dan berurutan. Disebut dengan waterfall karena tahap demi tahap yang dilalui harus menunggu selesainya tahap sebelumnya dan berjalan berurutan.

Waterfall atau air terjun adalah model yang dikembangkan untuk pengembangan perangkat lunak, membuat perangkat lunak. model berkembang secara sistematis dari satu tahap ke tahap lain dalam mode seperti air terjun.

Model ini mengusulkan sebuah pendekatan kepada pengembangan software yang sistematikdan sekuensial yang mulai dari tingkat kemajuan sistem pada seluruh analisis, desain, kode, pengujian dan pemeliharaan. Model ini melingkupi aktivitas-aktivitas sebgai berikut : rekayasa dan pemodelan sistem informasi, analisis kebutuhan, desain, koding, mengujian dan pemeliharaan.

Model pengembangan ini bersifat linear dari tahap awal pengembangan system yaitu tahap perencanaan sampai tahap akhir pengembangan system yaitu tahap pemeliharaan. Tahapan berikutnya tidak akan dilaksanakan sebelum tahapan sebelumnya selesai dilaksanakan dan tidak bisa kembali atau mengulang ke tahap sebelumnya. 


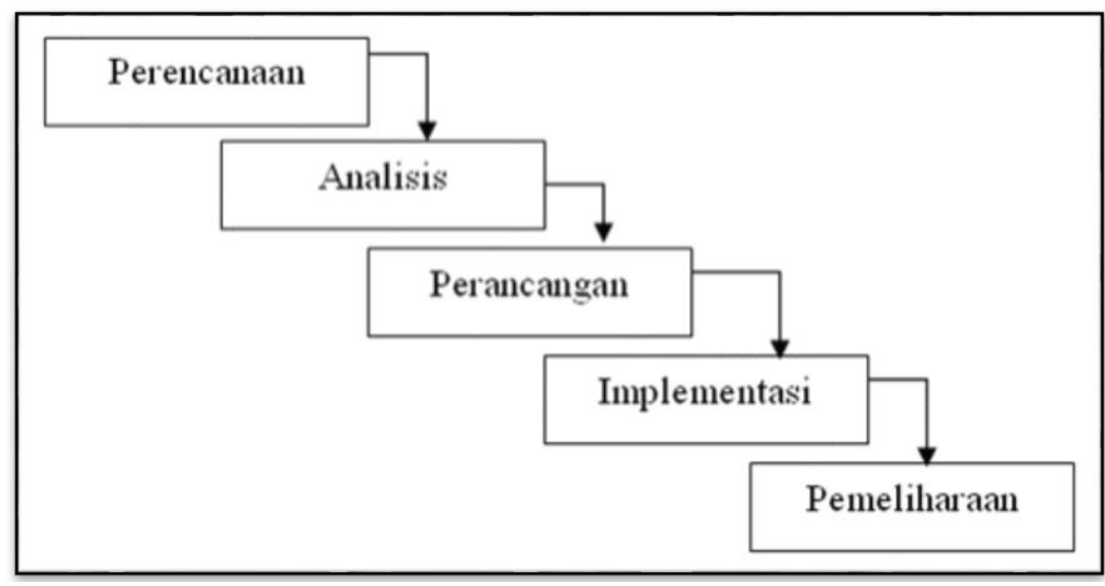

Gambar 3.1 Model Waterfall

\section{ANALISIS SISTEM}

Analis sistem adalah penguraian dari suatu sistem informasi yang utuh kedalam bagian-bagian komponennya dengan maksud mengidentifikasikan dan mengevaluasi permasalahan-permasalahan, kesempatan-kesempatan, hambatan-hambatan yang terjadi dan kebutuhan-kebutuhan yang diharapkan sehingga dapat diusulkan perbaikan-perbaikannya (Jogiyanto, 2005). Berikut merupakan hasil analis sistem perekrutan karyawan pada PT. Ria Indah Mandiri. Dari hasil analisa ini dapat diketahui permasalahan-permasalahan yang ada sistem yang berjalan, sehingga dapat ditemukan solusi untuk menangani permasalahan perekrutan karyawan.

\subsection{Uraian Prosedur Sistem Perekrutan Karyawan yang Sedang Berjalan}

Sistem perekrutan yang sedang berjalan pada PT. Ria Indah Mandiri memiliki tahapantahapan dalam melakukan proses kegiatannya.

Tahapan-tahapan tersebut adalah segabai berikut:

1 Divisi Supervisor mengisi formulir permintaan karyawan dengan lengkap.

2 Setelah mengisi dengan lengkap, divisi terkait mengirimkan formulir permintaan ke Store Manager.

3 Apabila disetujui Store Manager, Supervisor langsung memproses permintaan tersebut.

4 Setelah disetujui, Supervisor memproses formulir tersebut dan memeriksa data pelamar yang sudah masuk sebelumnya. Apabila tidak ditemukan data pelamar yang sesuai dengan kriteria, supervisor melakukan proses pencarian karyawan dengan memuat iklan atau brosur yang ditempatkan di daerah oprasional perusahaan/toko cabang.

5 Pelamar mengirim surat lamaran kerja dan daftar riwayat hidup (curriculum vitae) kepada Supervisor.

6 Dari data pelamar yang masuk, Supervisor melakukan proses seleksi berdasarkan spesipikasi yang dibutuhkan seperti riwayat pendidikan, pengalaman bekerja, pengalaman organisasi, keahlian, surat keterangan dokter, dan lain-lain.

7 Setelah menyeleksi, Supervisor mengirim surat panggilan wawancara (interview) kepada pelamar yang lulus seleksi.

8 Pelamar datang ke perusahaan untuk wawancara dengan bagian perekrutan karyawan Supervisor.

9 Selain melakukan wawancara dengan pelamar, Supervisor juga menginformasikan beberapa hal terkait dengan penempatan kerja, gajih serta fasilitas yang didapat, selama 
bekerja di perusahaan. Apabila pelamar yang diwawancarai sesuai dengan kriteria yang dibutuhkan, supervisor langsung melakukan kesepakatan kerja dengan pihak pelamar.

\section{PERANCANGAN SISTEM \\ 5.1 Use Case Diagram}

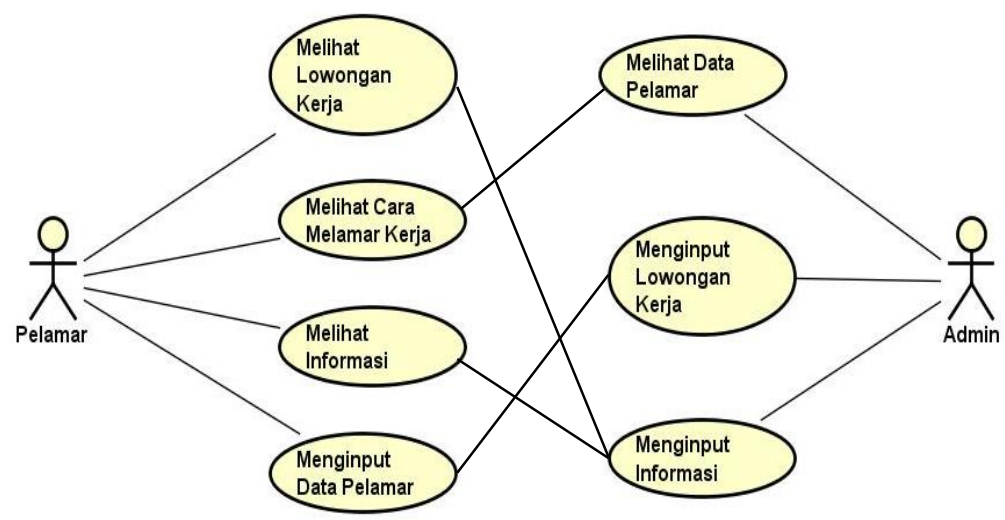

Gambar 5.1 Use Case Diagram System

Pada diagram use case sistem ini menggambarkan actor dan hubungannya dengan fungsi-fungsinya masing-masing. Dalam sistem informasi ini yang dikembangkan terdapat 2 aktor yaitu, Pelamar dan Admin/Spv/Hrd.

Pelamar memiliki fungsi diantaranya dapat melihat lowongan kerja, melihat cara melamar kerja, melihat informasi, dan menginputkan data pelamar kerja. Sedangkan Admin/Spv/Hrd memiliki fungsi diantaranya melihat data pelamar, menginput lowongan kerja, dan menginput informasi. Fungsi yang ada pada actor Pelamar dan Admin/Spv/Hrd harus melalui use case login terlebih dahulu.

1. Use Case Diagram Pelamar

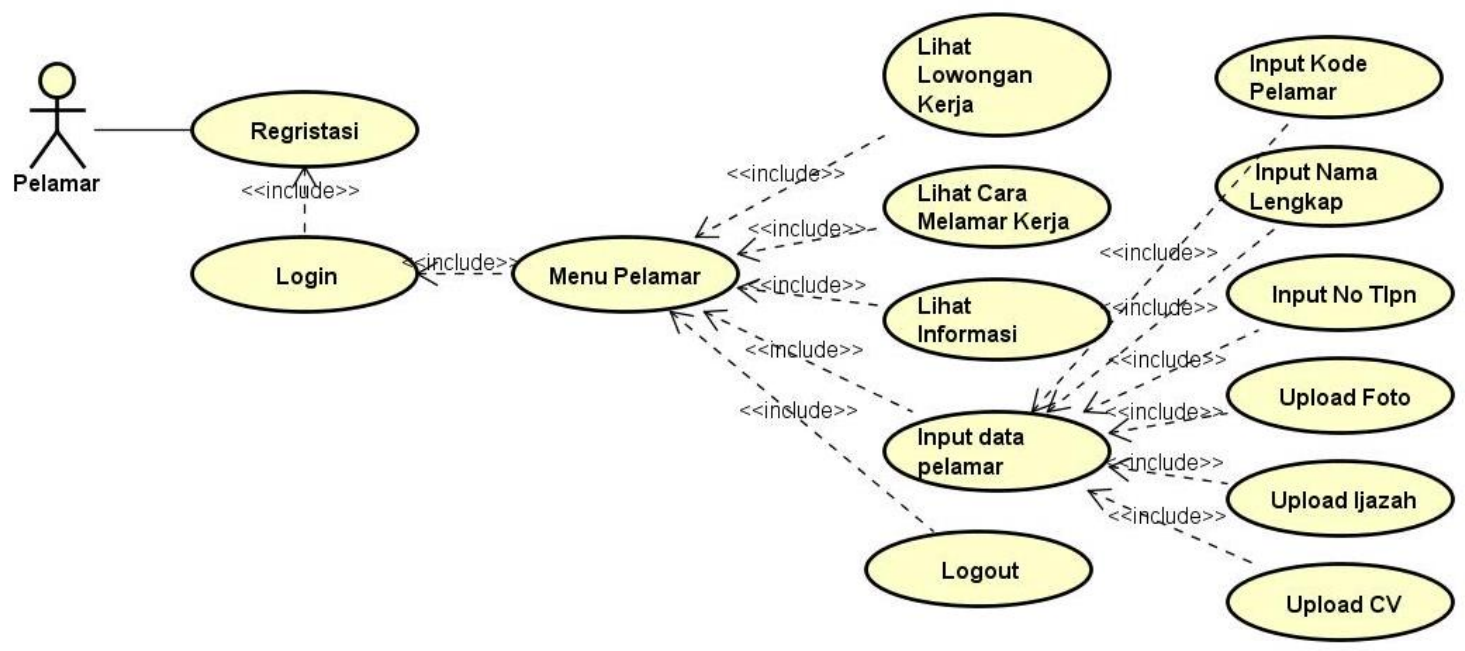

Gambar 5.2 Use Case Diagram Pelamar

Pada diagram use case ini pelamar memiliki hak akses terbatas terhadap pengelolaan sistem informasi. Fungsi pelamar diantaranya, melihat lowongan kerja, melihat cara melamar kerja, melihat informasi dan menginput data pelamar kerja. 
Syarat untuk mengakses fungsi tersebut pelamar harus melalui fungsi regristasi dan di lanjutkan ke funsi login sebagi user. Kemudian pada fungsi input data pelamar terdapat beberapa fungsi tambahan sesuai dengan kebutuhannya masing masing.

\section{Use Case Diagram Admin}

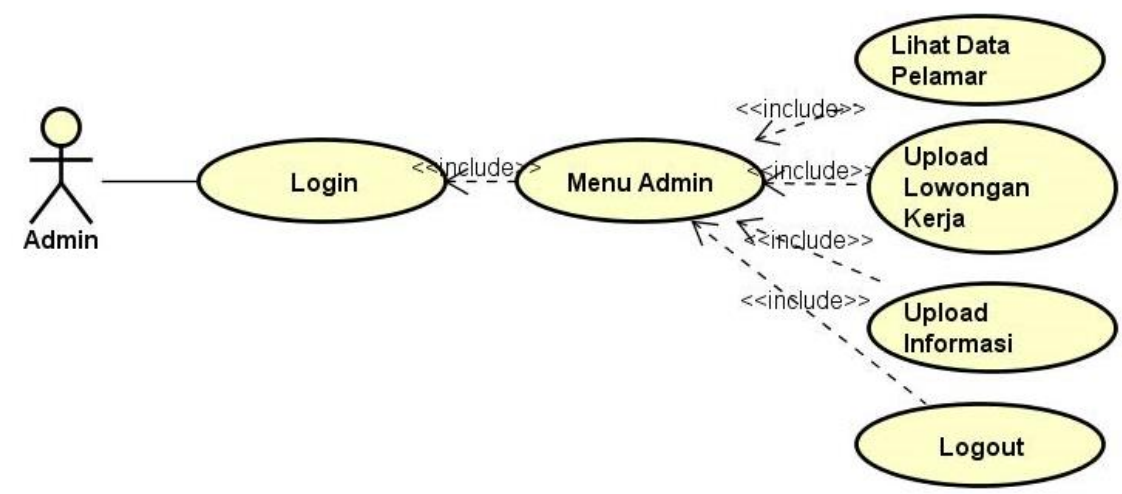

Gambar 5.3 Use Case Diagram Admin

Pada diagram use case ini fungsi admin diantaranya adalah melihat data pelamar yang sebelumnya sudah di upload oleh pelamar, mengupload lowongan kerja terupdate, dan mengupload informasi hasil seleksi. Syarat untuk mengakses fungsi tersebut adalah harus melalui fungsi login sebagai admin terlebih dahulu.

\subsection{Rancangan Layar}

1. Tampilan Register

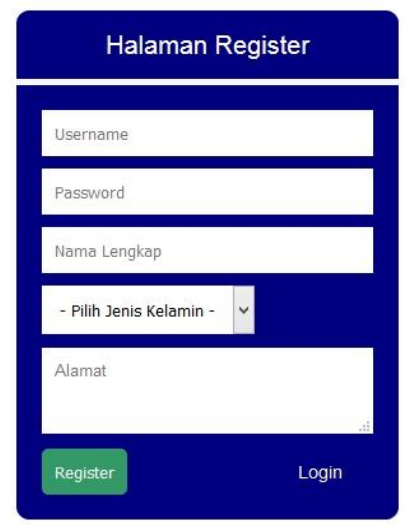

Gambar 5.4 Rancangan Layar Tampilan Register 
2. Tampilan Login

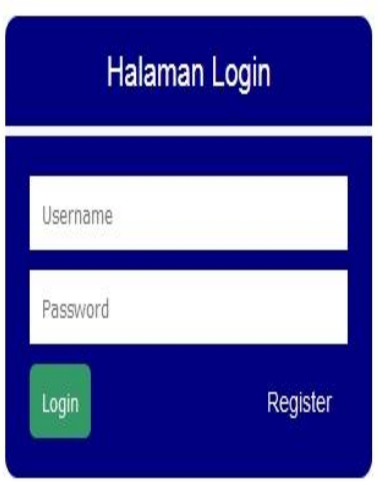

Gambar 5.5 Rancangan Layar Tampilan Login

3. Tampilan Menu Utama Pelamar

\section{PT. RIA INDAH MANDIRI}

Beranda Profil Produk Karir Input Data Pelamar Hubungi Kami

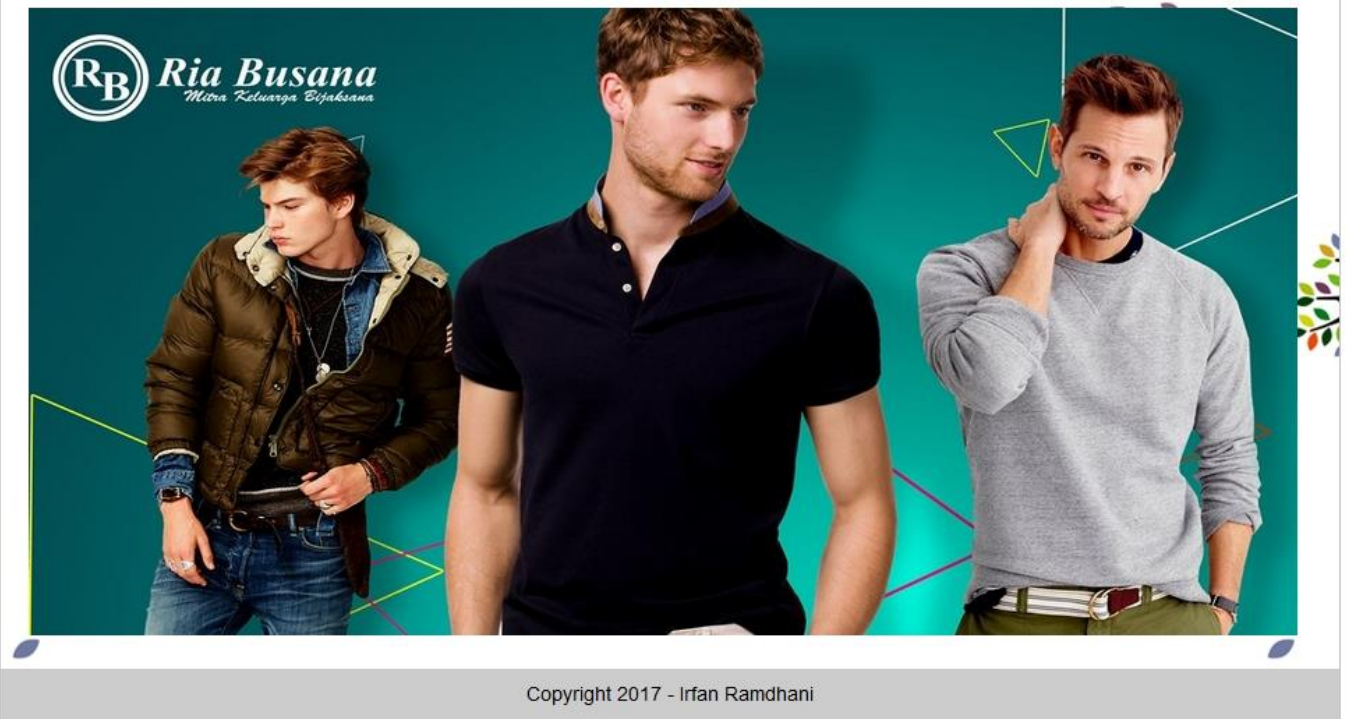

Gambar 5.6 Rancangan Layar Tampilan Menu Utama Pelamar

4. Tampilan Menu Input Data Pelamar 


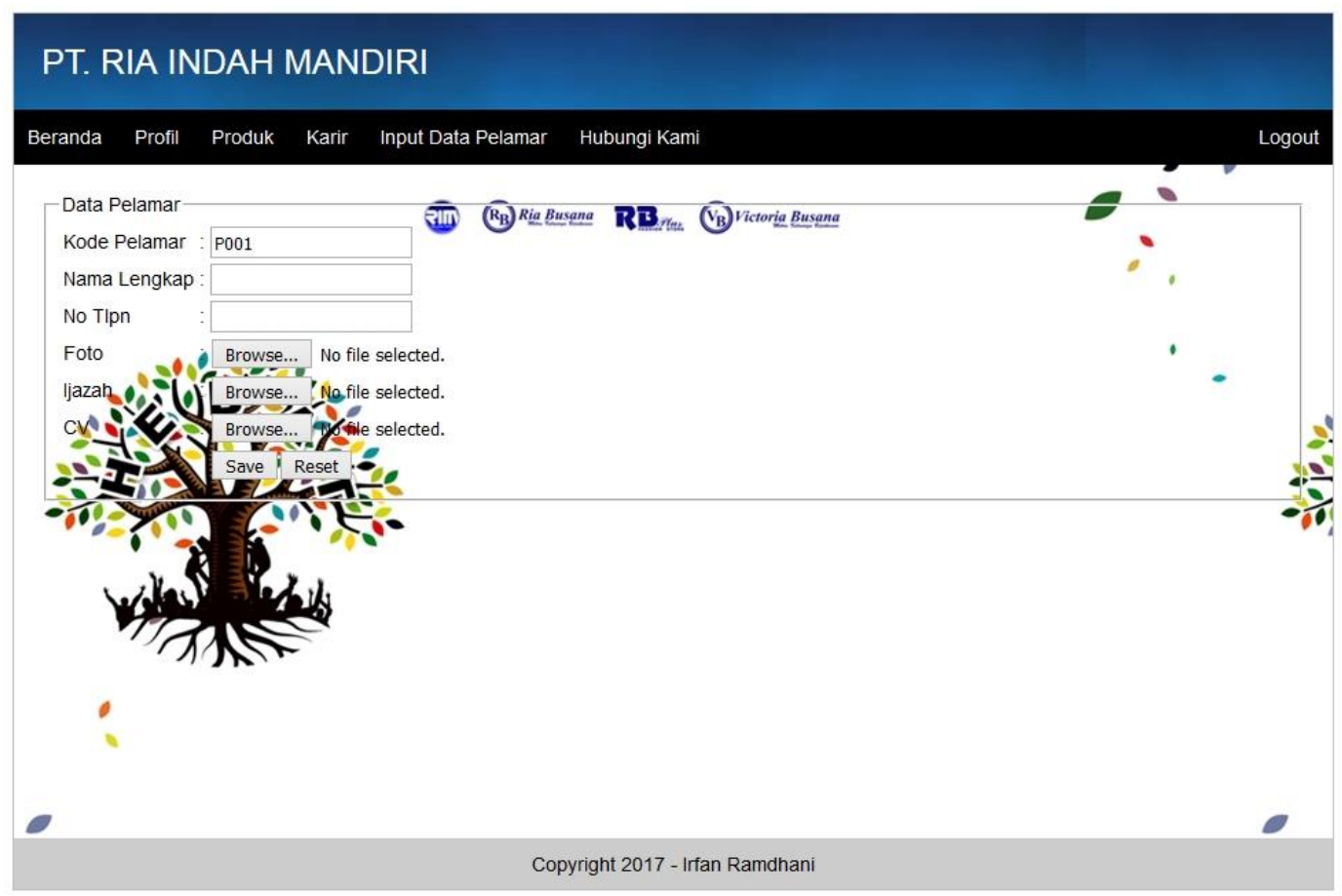

Gambar 5.7 Rancangan Layar Tampilan Menu Input Data Pelamar

5. Tampilan Menu Data Pelamar

\section{PT. RIA INDAH MANDIRI}

Data Pelamar Input Lowongan Kerja Input Informasi

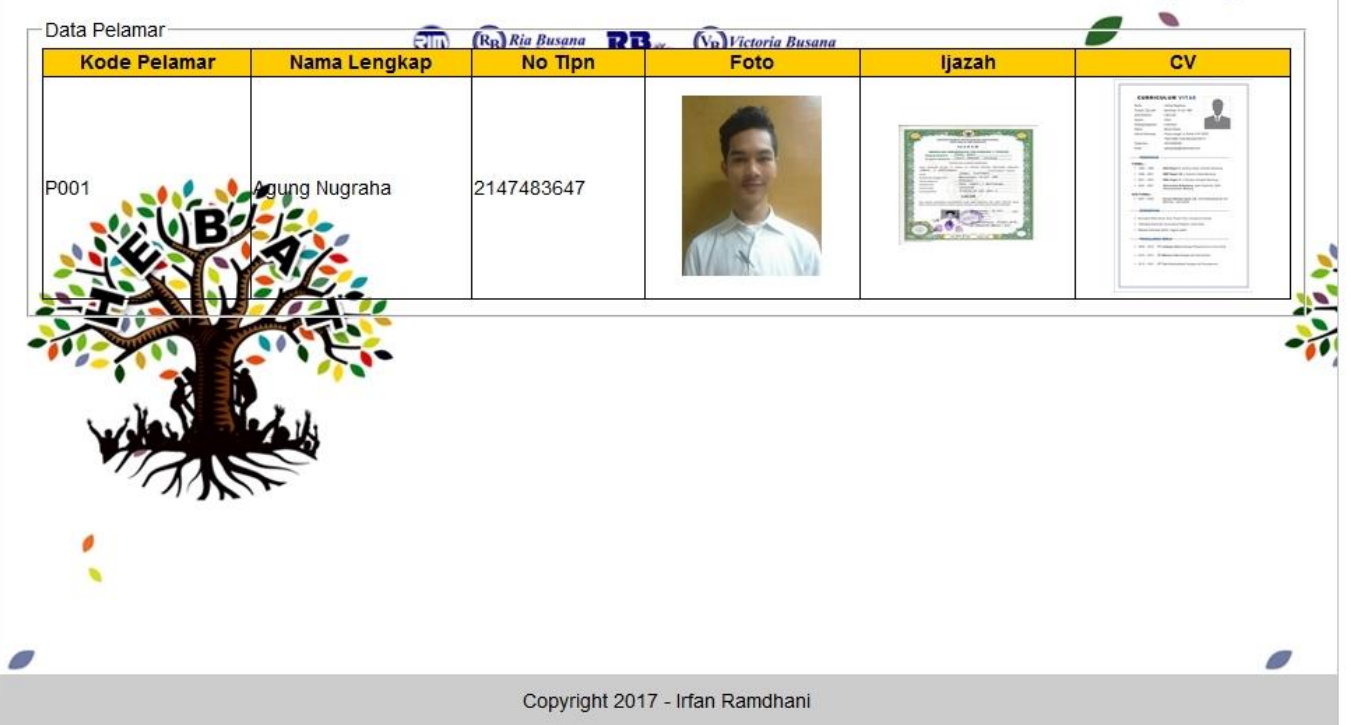

Gambar 5.8 Rancangan Layar Tampilan Menu Data Pelamar

\section{KESIMPULAN}

a. Sistem informasi perekrutan karyawan berbasis web dapat mengurangi besarnya biaya yang harus dikeluarkan oleh perusahaan setiap kali akan merekrut karyawan. 
b. Sistem informasi perekrutan karyawan menyajikan informasi yang dapat mempermudah bagian HRD / Spv PT. Ria Indah Mandiri dalam menangani proses perekrutan karyawan. Sehingga data pelamar tidak menumpuk di lemari arsip.

c. Sistem informasi perekrutan karyawan menyajikan informasi perekrutan karyawan yang dapat di akses oleh calon karyawan secara mudah dan cepat tanpa harus datang langsung ke perusahaan.

\section{DAFTAR PUSTAKA}

[1] Fathansyah, Ir, 2002, "Basis Data", Informatika, Bandung.

[2] Indrajit, 2001, Analisis dan Perancangan Sistem Berorientasi Object. Bandung, Informatika.

[3] Jogianto HM. 2005. Sistem Teknologi Informasi. Andi. Yogyakarta.

[4] Robert G Murdick, dkk, Sistem Informasi Untuk Manajemen Modern, Jakarta: Erlangga, 1991.

[5] Jogiyanto HM. 2005. Analisis \& Desain Sistem Informasi : Pendekatan Terstruktur Teori dan Praktek Aplikasi Bisnis. Yogyakarta. Andi.

[6] Gordon B. Davis, Kerangka Dasar Sistem Informasi Manajemen Bagian 1, PT Pustaka Binamas Pressindo, Jakarta: 1991.

[7] Dr. Ir. Harijono Djojodihardjo, Pengantar Sistem Komputer, Erlangga, Bandung: 1984.

[8] Lani Sidharta, Pengantar Sistem Informasi Bisnis, P.T. ELEX Media Komputindo, Jakarta: 1995

[9] Cerdas berbahasa Indonesia, Hal : 130-131, Penerbit : Erlangga.2006.Jakarta, Penulis : Engkos Kosasih).

[10] Tata Sutabri, Sistem Informasi Manajemen, 2005, Yogyakarta, Andi.

[11] Mcleod, Raymond, 2001, Sistem Informasi Manajemen, Jakarta, PT. Prenhallindo.

[12] Arbie, E., 2000, Pengantar Sistem Informasi Manajemen, Edisi Ke-7, Jilid 1, Bina Alumni Indonesia, Jakarta.

[13] Muhyuzir T.D., 2001, Analisa Perancangan Sistem Pengolahan Data, Cetakan Kedua, PT. Elex Media Komputindo, Jakarta.

[14] Jogianto2 HM. 2005. Sistem Teknologi Informasi. Andi. Yogyakarta.

[15] Jogiyanto HM., Analisis dan Disain Informasi: Pendekatan Terstruktur Teori dan Praktek Aplikasi Bisnis, Andi Offset, Yogyakarta: 1999.

[16] Gordon B. Davis, Kerangka Dasar Sistem Informasi Manajemen Bagian 1, PT Pustaka Binamas Pressindo, Jakarta: 1991.

[17] https://desihidayani.wordpress.com/2015/09/20/basis-data-database/

[18]https://id.wikipedia.org/wiki/Internet\#Sejarah_Internet

[19] http://rina12tkj1.blogspot.co.id/2013/11/pengertian-sejarah-dan-fungsi-dari.html

[20] http://infodanpengertian.blogspot.co.id/2015/04/pengertian-karyawan-menurut-paraahli.html\#

[21] http://kapanpunbisa.blogspot.co.id/2013/05/pengertian-diagram-alir-data-dataflow.html

[22] https://id.wikipedia.org/wiki/Flock

[23] http://evafinufa25.blogspot.com/2013/04/rpl-tentang-model-waterfall.html

[24] http://definisiahli.blogspot.co.id/2014/11/definisi-perancangan-sistem-menurutahli.html

[25] http://www.sarjanaku.com/2012/11/pengertian-sistem-informasi-menurut.html 